\title{
Tensile Strength of Threaded Rods Made by 3D Printing of Polymeric Material
}

\author{
MARIUS IONUT RIPANU ${ }^{1}$, ANDREI MARIUS MIHALACHE ${ }^{1}$, LAURENTIU SLATINEANU ${ }^{1}$, \\ MARIAN MARES ${ }^{2}$, LIVIU ANDRUSCA ${ }^{2}$, ADELINA HRITUC ${ }^{1 *}$, OANA DODUN ${ }^{1}$, \\ GHEORGHE NAGIT ${ }^{1}$, MARGARETA COTEATA ${ }^{1}$, BRUNO RADULESCU ${ }^{3}$ \\ 1 "Gheorghe Asachi" Technical University of Iași, Faculty of Machine Manufacturing and Industrial Management, \\ Department of Machine Manufacturing Technology, 39A D. Mangeron Blvd., 700050, Iasi, Romania \\ 2 "Gheorghe Asachi” Technical University of Iași, Faculty of Mechanical Engineering, Department of Mechanical \\ Engineering, Mechatronics and Robotics, 43 D. Mangeron Blvd., 700050 Iasi, Romania \\ 3 "Gheorghe Asachi" Technical University of Iasi, Faculty of Machine Manufacturing and Industrial Management, \\ Department of Machine Tools, 59A D. Mangeron Blvd., 700050, Iasi, Romania
}

Abstract: The extension of $3 D$ printing processes for parts made of polymeric materials highlighted the possibility of manufacturing threaded surfaces through such processes. In principle, the operation of a threaded joint involves tensile forces in the threaded rod. The dimensional characteristics of the threaded surface and some input factors in the $3 D$ printing process can influence the tensile strength of threaded rods made of polymeric materials. An experimental research aimed at the tensile behavior of a threaded joint was designed, using a plastic screw and a special steel nut. A factorial experiment was designed and implemented to identify an empirical mathematical model capable of highlighting the influence of the dimensional characteristics of the threaded surface and some of the input factors in the $3 D$ printing process on tensile strength. The test samples from polymeric materials were manufactured by $3 D$ printing, then subjected to tensile tests. The mathematical processing of the experimental results allowed the determination of a mathematical model that allows the inclusion of the ordering of the factors taken into account in terms of the intensity of the influence that these factors exert on the tensile strength of the threaded rods. It was found that the diameter of the threaded rod exerts the strongest influence on the tensile strength of the threaded rod obtained by $3 D$ printing, increasing the diameter of the threaded rod causing an increase in the maximum deformation of the rod. Increasing the thread pitch leads to a decrease in the maximum deformation of the threaded rod.

Keywords: threaded rod, polylactic acid, 3D printing, tensile strenght, empirical mathematical model

\section{Introduction}

Threads are surfaces that are obtained as a result of the movement of a certain contour along a spiral placed on a cylindrical, conical or spherical surface. Currently, there are threads used to transmit a movement, to assemble several parts together and threads for special purposes. There is still the possibility to classify the threads by taking into account their location on external or internal surfaces, the pitch, the direction of the arrangement of the spiral, the units of measurement, the profile in cross section on the thread axis, etc.

The existence of a threaded joint needs the presence of a threaded rod and a nut.

In principle, during operation, the threaded rods can be applied to tensile, compression, buckling, bending and torsion. Threaded steps on a rod can also be affected by shearing stresses.

There is a wide variety of materials from which the elements of a threaded joint can be made. Steels are mainly used as such materials, but there are also situations when threaded parts are made of cast iron, non-ferrous metals and alloys, plastics, wood.

The threads existing on the metal parts can be obtained by cutting, by plastic deformation and by some nonconventional machining processes, respectively.

*email:hrituc.adelina3295@yahoo.com 
The expansion of the use of plastics [1] has led, among other things, to the manufacture of the components of a threaded joint of these materials. As additive methods for the manufacture of metal parts have emerged and developed in recent decades, it has been normal for such methods to be applied also to the manufacture of the components of a threaded joint.

In principle, additive methods involve the gradual generation of a part by the successive addition of layers of material using processes based on distinct physical-chemical processes.

Currently, there are several additive manufacturing methods, among which there are fused deposition modeling, digital light processing, selective laser sintering, stereolithography, etc.

The so-called fused deposition modeling is an additive manufacturing process in which the layers of material that will gradually form the part arise from the controlled melting of a wire from the material to be deposited and the arrangement of the molten material along predetermined trajectories. The different properties of use of the materials of the parts obtained by fused deposition modeling can be significantly influenced by the values of some factors that characterize the deposition process.

As in many cases, the plastic components of a threaded joint are subjected to various mechanical stresses. The investigation of how they can be manufactured and how they behave under the action of mechanical stresses such components have been the objectives of scientific research.

Thus, Patpatiya and Shastri investigated the possibilities of manufacturing thermoplastic fasteners based on the use of M8 threaded joints [2]. They used the ANOVA method to establish the optimal printing conditions, aiming to reduce the dimensional deviations of the manufactured parts when applying the photopolymer jetting technology.

Wang et al. used 3D printing process to generate and study the mechanical properties of expandable casing threads working in corrosion conditions [3]. They concluded that such threads for expandable casing can be made efficiently when using a three-stage design.

Sydor and Wołpiuk have shown that it is economical to use 3D printing processes to make threaded joints for the assembly of wood products, and the use of metal fasteners is not justified. They applied a manufacturing technology based on fused deposition modeling [4].

Addressing general issues connected to the design of machine parts for manufacturing through 3D printing processes, Lusk analyzed some practical aspects of obtaining screw threads [5].

MacLeod et al. set out to study the possibilities of manufacturing 3D printed locking osteosynthesis screw threads [6]. They proved that screw drives thus obtained have a strength comparable to that of machined or hand tapped screw threads, the latter being considered to be manufactured by traditional processes.

In the present paper, the development of an investigation regarding the tensile behavior of threaded rods made by $3 \mathrm{D}$ printing from polylactic acid was considered.

\section{Materials and methods}

\subsection{The stresses to which the threads and threaded parts are subjected}

The main components of a threaded joint are the rod which has a thread on the outer surface and the nut which has the thread on the inner surface of the hole. For both the threaded rod and the nut there are dimensions that define the characteristics of the standardized thread, between them being major and minor diameters, pitch and pitch diameter, etc. The values of some of these dimensions can have a significant influence on the behavior of the threaded component under the action of mechanical stresses.

As mentioned above, the stresses generated in the threaded rods during the operation of the threaded joint can be tensile, compression, buckling, bending and twisting.

Taking into account a threaded rod subjected to tensile stresses, it will be found that in the area of the thread turns a shear stress is generated in addition.

To test the tensile behavior of a plastic threaded rod, a test scheme supposing the use of a special steel nut was applied (Figure 1). Given the pronounced difference in hardness and strength of mechanical stress between the steel of the special nut and the polylactic acid from which the threaded rod is made, it is possible that crushing stresses may occur, and it is assumed that the material that will yield first is 
plastic of the threaded rod.

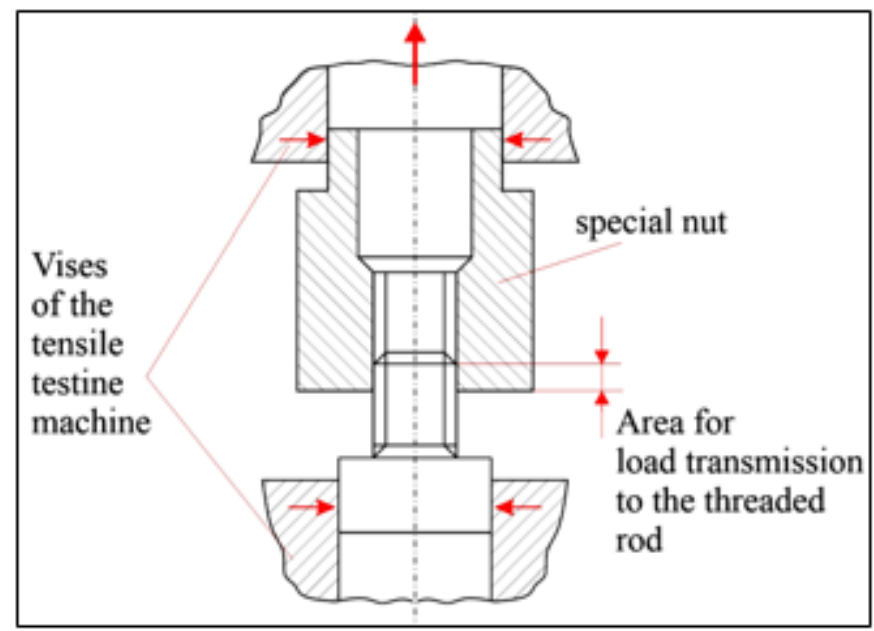

Figure 1. Schematic designed to investigate the tensile behavior of the threaded rod

In Figure 2, a detail of the joint area of the special steel nut and the polylactic acid threaded rod can be seen. During the tensile test, due to the upward movement of the special nut, the profile of a spiral turn of the polylactic acid threaded rod will come into contact with the special nut at the flank in the lower part of the turn, on the opposite side there is a clearance between the flanks of the turns on the threaded rod and respectively on the special nut. Tensile forces will be generated in the polylactic acid threaded rod, but shear forces are expected to occur in the contact area of the turn on the plastic rod with the turn on the steel nut. If the shear forces are large enough, it is expected that the rod thread made of polylactic acid will be damaged by shearing of the turn (Figure 2).

The existence of the spiral channel specific to the thread can cause the appearance of stress concentrators that could lead to a breaking of the rod in the threaded area.

A stress concentrator can also be generated by the sharp angle of joining the threaded rod area with a larger diameter rod, which could also cause the threaded rod to break in this area.

The above aspects allow us to notice that, in relation to the specific dimensions of the thread, it is possible to damage in different areas of the polylactic acid rod during the tensile test.

The mechanical properties of the material from which the threaded part is made (polylactic acid), but

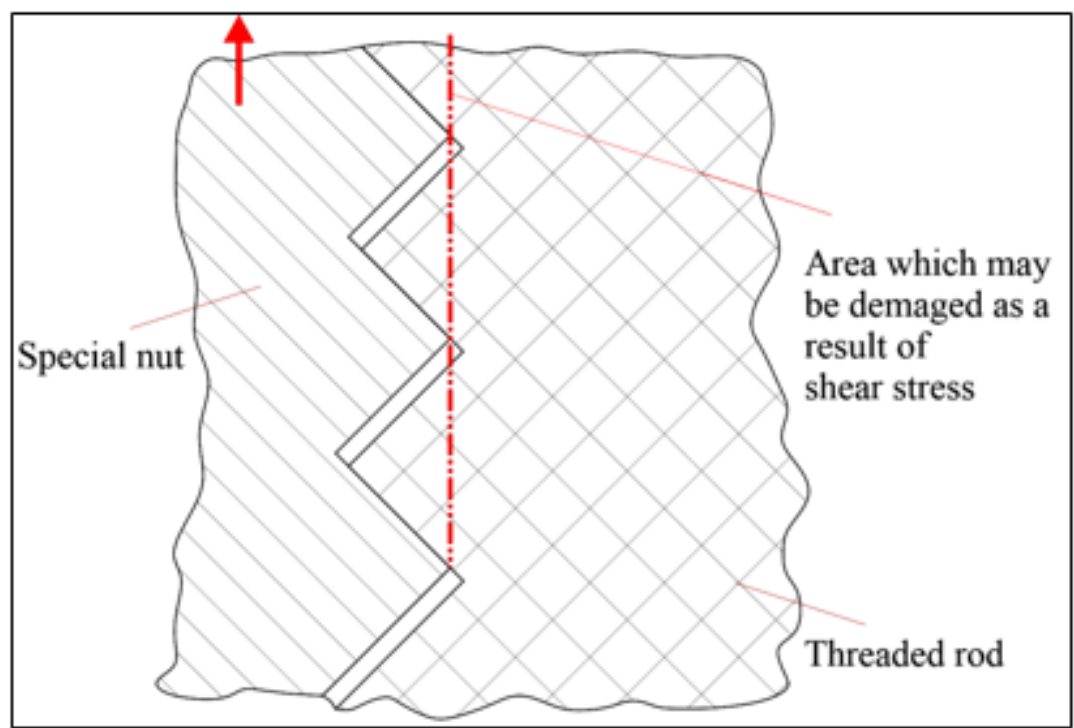

Figure 2. Area where a spiral shearing process was assumed to develop 
also some sizes specific to the 3D printing process, can exert influence on the possible damage of the threaded rod, if the threaded rod was obtained by such a process.

The results of a modeling of the stress state of the screw affected by tensile using the finite element method can be seen in Figure 3. The modeling was performed using ANSYS 2019 software. It is noticed that there is a high stress in the area of the turns through which the plastic screw comes into contact with the special nut.

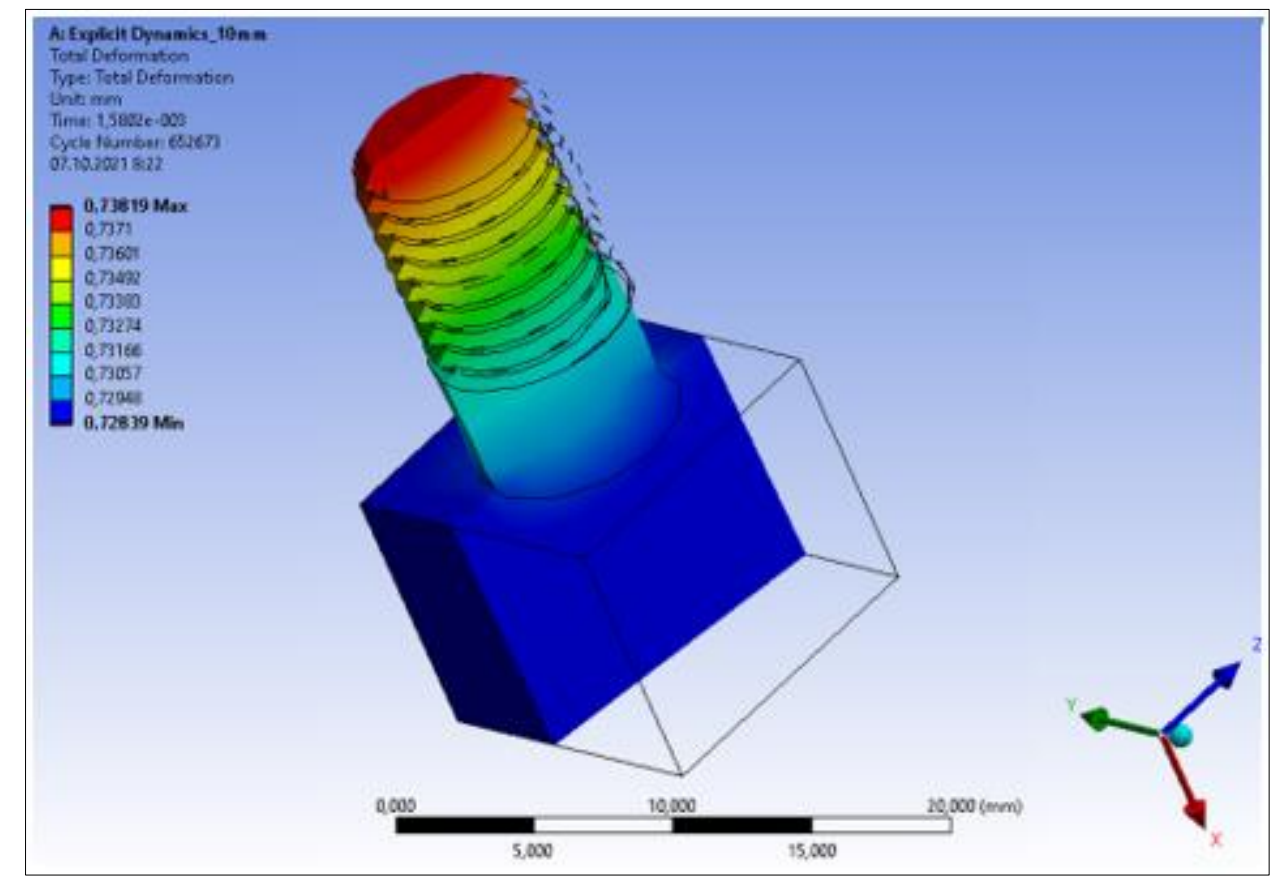

Figure 3. Modeling by the finite element method of the stress state of the screw subjected to the tensile test

\subsection{Tensile test of a plastic threaded rod}

The main objective of the research whose results have been presented in this paper was to investigate the tensile behavior of a threaded rod obtained by 3D printing.

For this purpose, the tensile test schematic shown in Figure 1 was taken into account.

The nut has a square cross-section at the top (Figure 4b), which allows a sufficiently secure clamping of the special nut in the vise found at the top of working zone of the tensile test machine.

During the test, to ensure conditions for shear damage of the thread found on the threaded rod of the screw, only a small number of turns of the rod entering the nut were used.

\subsection{Experimental conditions}

An experimental program was designed to facilitate the tracking of the behavior of the polylactic acid threaded rod under the action of tensile stresses.

A screw-type part having the shape specified in Figure 4a was first designed for this purpose. Intending to determine also the influence exerted on the behavior of the threaded rod at tensile by some dimensions of the thread, threaded rods with metric threads type M8x1, M8x1.25, M10x1 and M10x1.25 were previously machined. It can be seen that if the M8x1.25 thread corresponds to a normal thread, the other three categories of threads are fine pitch threads. An Ultimaker 2+ printer (made in Netherlands) was used for 3D printing. A wire of polylactic acid was used for deposition.

The experimental tests were performed on a WDW type universal tensile testing machine (made in China).

To reduce the duration of the experimental tests, the use of a fractional factorial experiment of type 
$\mathrm{L}_{8}\left(2^{7-4}\right)$ was considered, in accordance with the requirements formulated by Taguchi [7]. The experiment allows the use of seven input factors corresponding to independent variables with values at two levels.

As dimensional characteristics of the thread, two values of major diameter, pitch and, initially, of the length of the threaded step of the rod in contact with the thread of the nut were taken into account.

As the $\mathrm{L}_{8}$ factorial experiment allows the use of 7 independent variables (corresponding to input factors in the tensile test process), it has become possible to analyze the inclusion as input factors and some features of the $3 \mathrm{D}$ printing process. There are a relatively large number of parameters that define a 3D printing process. An analysis of these factors revealed that the tensile strength of the threaded rod could be influenced by infill density $i$, layer thickness $l$, printing speed $v$, and cooling conditions c. Two levels of variation of these process input factors were established (maximum value and minimum value).

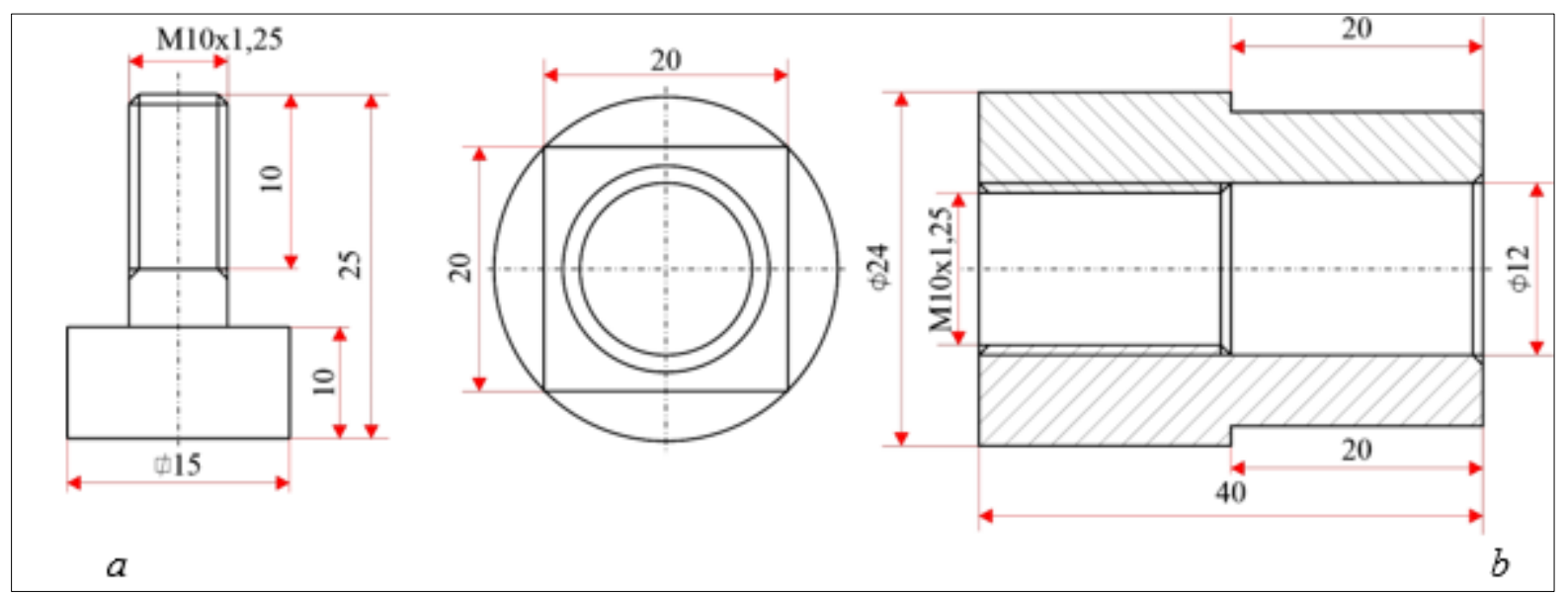

Figure 4. Example of a plastic threaded rod $(a)$ (designed as a threaded screw) and a special steel nut $(b)$

The coded and real values of the process input factors mentioned above have been entered in Table 1 .

One of the first preliminary experimental tests led to the observation that if the number of contact turns between the plastic threaded rod and the special steel nut is the one corresponding to the initial lengths of the threaded step, it is possible not to obtain a break by shearing the threaded turn, but a break by tensile in other areas of the threaded screw. Under these conditions, the initial tensile test program was modified to a small extent, using as input factor the number of turns $n_{t}$ included in the threaded joint between the screw and the nut, instead of the length of the threaded step initially considered. As levels of variation of the new input factor (number $n_{t}$ of turns in the threaded joint) were taken into account 2 , 3 and 4 turns of the thread respectively (Table 1).

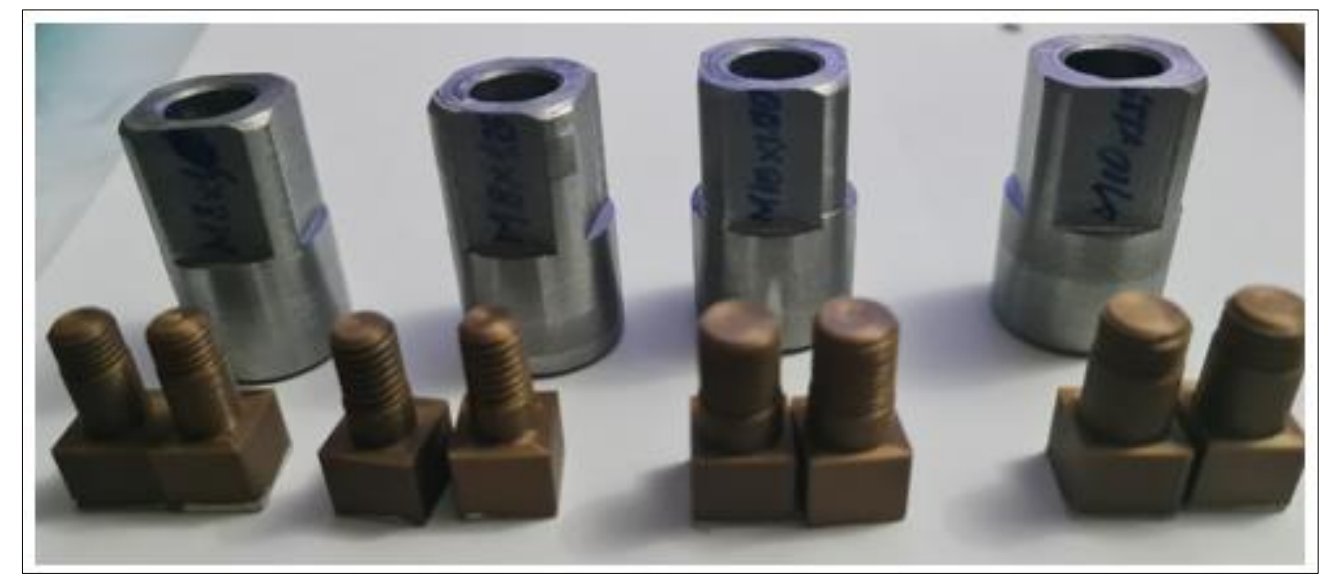


Figure 5. Special test pieces and nuts before performing the tensile test

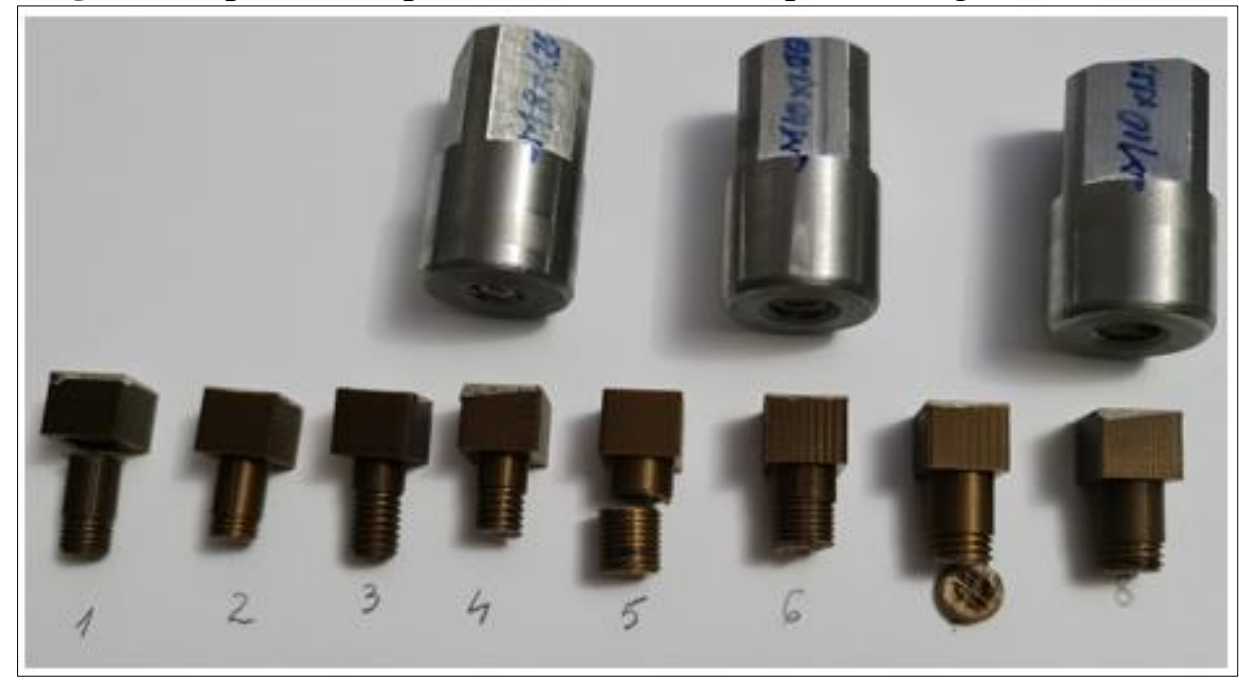

Figure 6. Test pieces (1-8) after performing the 8 experimental tests, revealing the initiation and possibly the development of the breaking process in different steps of the screws

Images of plastic test pieces obtained by $3 \mathrm{D}$ printing and special steel nuts before performing the 8 experimental tests can be seen in Figure 5, while images of the test pieces after the experimental test could be seen in Figure 6 . The test speed was $0.2 \mathrm{~mm} / \mathrm{min}$. Interesting aspects regarding the deformations generated in the test piece during the tensile test can be observed in Figure 7.

\section{Results and discussions}

Figure 8 shows the load-deformation diagrams for all 8 experimental tests performed in accordance with the principles of a fractional factorial experiment of Taguchi $\mathrm{L}_{8}$ type. The values of the maximum tensile force at which the failure of the test pieces occur were entered in column no. 8 of Table 1.

Examination of the diagrams in Figure 8 showed a fairly similar behavior of the threaded rods in the tensile test.

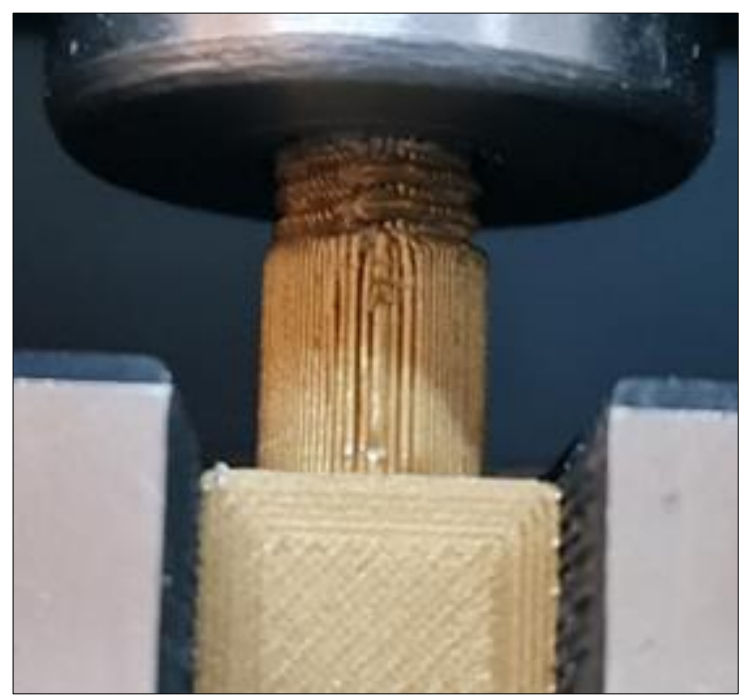

Figure 7. Appearance of a test piece during the tensile test

There is an initial increase in load, followed by a horizontal evolution of the curve and a subsequent increase to a value at which the process of breaking the test piece begins. The first increase in load was 
considered to correspond to the gradual loading of the first turn, so that the second increase meant the gradual loading of the second turn of the thread. Further increase of the load may, at some point, cause the test piece to rupture.

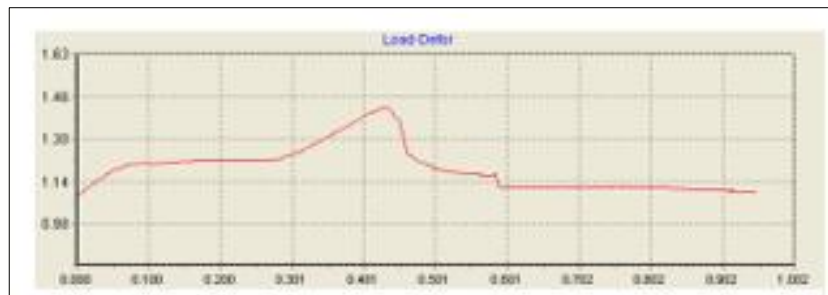

ExD. no. 1

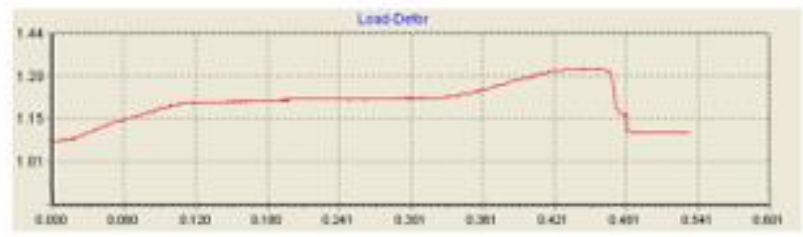

Exp. no. 3

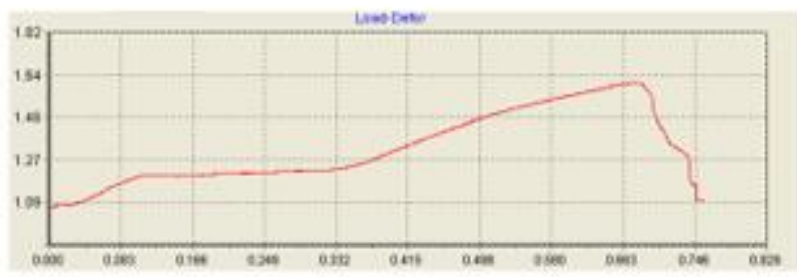

Exp. no. 5

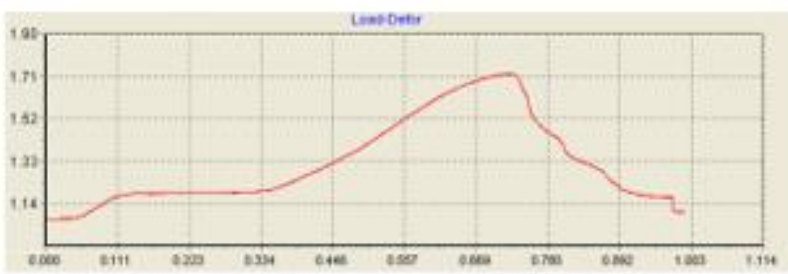

Exp. no. 7

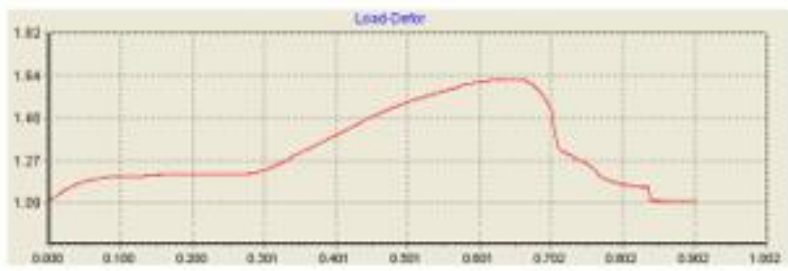

Exp. no. 2

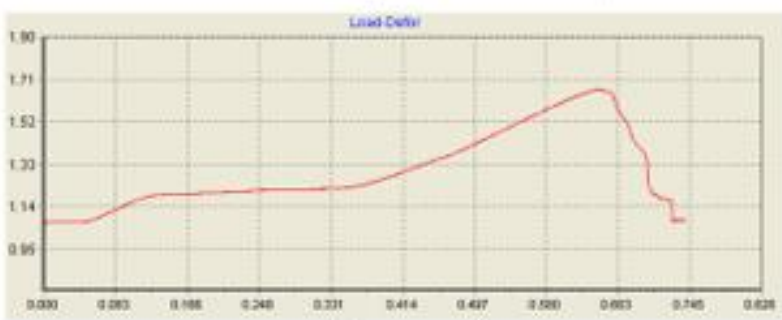

Exp. no. 4

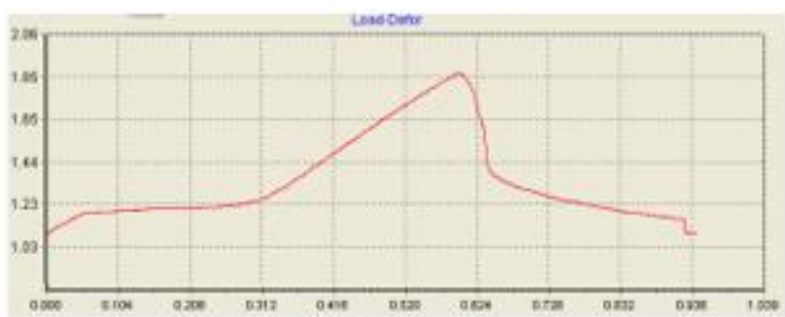

Exp. no. 6

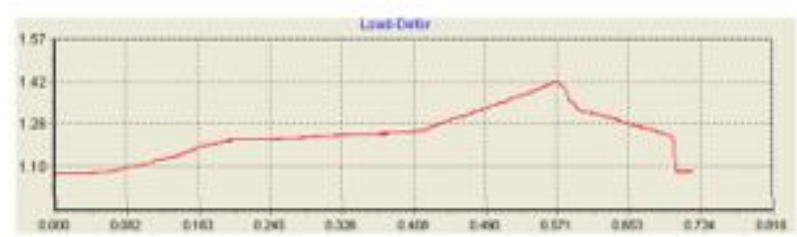

Exp. no. 8

Figure 8. Stress-strain curves obtained at tensile tests for all the 8 experiments

Another fact observed in connection with which it will be necessary to design and carry out in the future an appropriate experimental program is that if in some cases the shearing of the turns is visible on the test pieces, in other cases the test piece broke in other areas, respectively in the area between the threaded and unthreaded surface of the screw or between the unthreaded step of the screw and its head (Figure 6).

It was considered that the existence of similarities in the shapes of the load-deformation curves would nevertheless allow the identification of an empirical mathematical model, in accordance with the assumptions initially adopted. This empirical mathematical model could highlight the influence exerted by the input factors mentioned above on the load at which the maximum deformation of the screw occurs, in accordance with the information entered in the load-deformation diagrams. 
Table 1. Experimental conditions and results $L_{8}\left(2^{7-4}\right)$

\begin{tabular}{|c|c|c|c|c|c|c|c|c|c|c|}
\hline \multirow{2}{*}{$\begin{array}{c}\text { Experiment } \\
\text { no. }\end{array}$} & \multicolumn{8}{|c|}{ Input factors (coded value/real value) } & \multirow{2}{*}{$\begin{array}{c}\begin{array}{c}\text { Output } \\
\text { parameter }\end{array} \\
\text { Maximum } \\
\text { load, F, N }\end{array}$} & \multirow[b]{2}{*}{ Remarks } \\
\hline & $\begin{array}{l}\text { Majordiameter } \\
\mathrm{d}_{\max }, \mathrm{mm}\end{array}$ & $\begin{array}{l}\text { Pitch } p, \\
\text { mm }\end{array}$ & $\begin{array}{c}\text { Threaded } \\
\text { length of } \\
\text { the rod, } l_{t} \text {, } \\
\mathrm{mm}\end{array}$ & $\begin{array}{c}\text { No. of } \\
\text { threaded } \\
\text { turns, } \\
\boldsymbol{n}_{\boldsymbol{t}}\end{array}$ & $\begin{array}{c}\text { Infildensity, } \\
\quad i, \%\end{array}$ & $\begin{array}{c}\text { Layer } \\
\text { thickness, } \\
\mathrm{mm}\end{array}$ & $\begin{array}{c}\text { Printing } \\
\text { speed, } v \text {, } \\
\mathrm{mm} / \mathrm{s}\end{array}$ & $\begin{array}{l}\text { Cooling, } \\
\quad c, \%\end{array}$ & & \\
\hline $\begin{array}{l}\text { Column } \\
\text { no. } 1\end{array}$ & 2 & 3 & 4 & & 5 & 6 & 7 & 8 & 9 & 10 \\
\hline 1 & $1 / 8$ & $1 / 1$ & $1 / 6$ & 4 & $1 / 25$ & $1 / 0.06$ & $1 / 20$ & $1 / 50$ & 340 & $\begin{array}{c}\text { No } \\
\text { breaking }\end{array}$ \\
\hline 2 & $1 / 8$ & $1 / 1$ & $1 / 6$ & 2 & $2 / 50$ & $2 / 0.15$ & $2 / 30$ & $2 / 100$ & 515 & $\begin{array}{l}\text { Separation } \\
\text { of the } \\
\text { loaded } \\
\text { turns }\end{array}$ \\
\hline 3 & $1 / 8$ & $2 / 1.25$ & $2 / 10$ & 3 & $1 / 25$ & $1 / 0.06$ & $2 / 30$ & $2 / 100$ & 250 & $\begin{array}{c}\text { No } \\
\text { breaking }\end{array}$ \\
\hline 4 & $1 / 8$ & $2 / 1.25$ & $2 / 10$ & 3 & $2 / 50$ & $2 / 0.15$ & $1 / 20$ & $1 / 50$ & 595 & $\begin{array}{l}\text { Breaking of } \\
\text { the loaded } \\
\text { turns }\end{array}$ \\
\hline 5 & $2 / 10$ & $1 / 1$ & $2 / 10$ & 3 & $1 / 25$ & $2 / 0.15$ & $1 / 20$ & $2 / 100$ & 525 & $\begin{array}{c}\text { Breaking } \\
\text { between the } \\
\text { threaded } \\
\text { step and the } \\
\text { unthreaded } \\
\text { step }\end{array}$ \\
\hline 6 & $2 / 10$ & $1 / 1$ & $2 / 10$ & 3 & $2 / 50$ & $1 / 0.06$ & $2 / 30$ & $1 / 50$ & 785 & $\begin{array}{l}\text { Breaking of } \\
\text { the loaded } \\
\text { turns }\end{array}$ \\
\hline 7 & $2 / 10$ & $2 / 1.25$ & $1 / 6$ & 2 & $1 / 25$ & $2 / 0.15$ & $2 / 30$ & $1 / 50$ & 650 & $\begin{array}{l}\text { Breaking of } \\
\text { the loaded } \\
\text { turns }\end{array}$ \\
\hline 8 & $2 / 10$ & $2 / 1.25$ & $1 / 6$ & 2 & $2 / 50$ & $1 / 0.06$ & $1 / 20$ & $2 / 100$ & 340 & $\begin{array}{l}\text { Breaking of } \\
\text { the loaded } \\
\text { turns }\end{array}$ \\
\hline
\end{tabular}

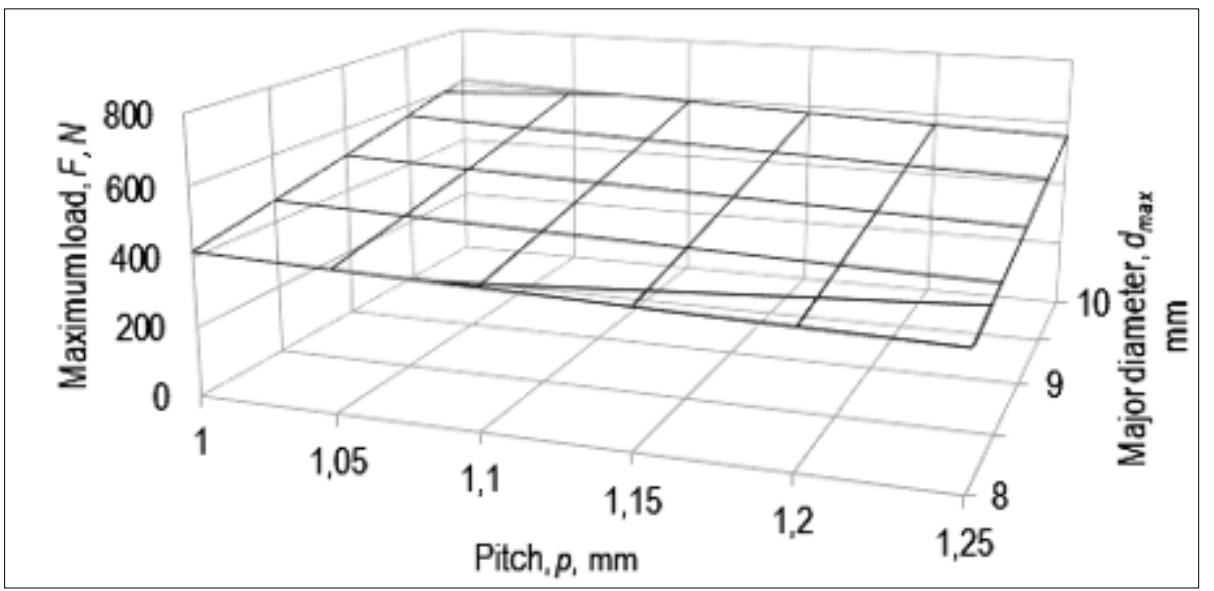

Figure 9. The influence exerted by the pitch $p$ and major diameter $d_{\max }$ on the value of the load at which the maximum deformation occurs

$$
\left(n_{t}=3, i=50 \%, t=0.06 \mathrm{~mm} . v=20 \mathrm{~mm} / \mathrm{s}, c=50 \%\right)
$$

For the mathematical processing of the experimental results was used a specialized software based on the method of least squares [8]. The software allows the selection of the most appropriate empirical mathematical model from 5 available models (first degree polynomial, second degree polynomial, power type function, logarithmic function, hyperbolic function) by taking into account the Gauss's criterion. Assuming a monotonous variation of the size of the output parameter (of the load $F$ at which the maximum deformation is recorded), it was preferred to use a power function model, as the exponents attached to the independent variables could provide better information concerning the direction and intensity of influence exerted by the input factors taken into account.

Mater. Plast., 58 (4), 2021, 9-18 
As described above, the following empirical mathematical model of power-type function has been determined:

$$
F=3.199 d_{\max }{ }^{1.782} p^{-0.496} n_{t}{ }^{0.496} i^{0.497} t_{h}{ }^{0.510} v^{0.581} c^{-0.417}
$$

Using this mathematical model, the diagrams in Figures 9 and 10 were drawn.

The analysis of the diagrams and the empirical mathematical model allowed the formulation of observations regarding the influence of the input factors on the load that determines the maximum deformation of the threaded rod.

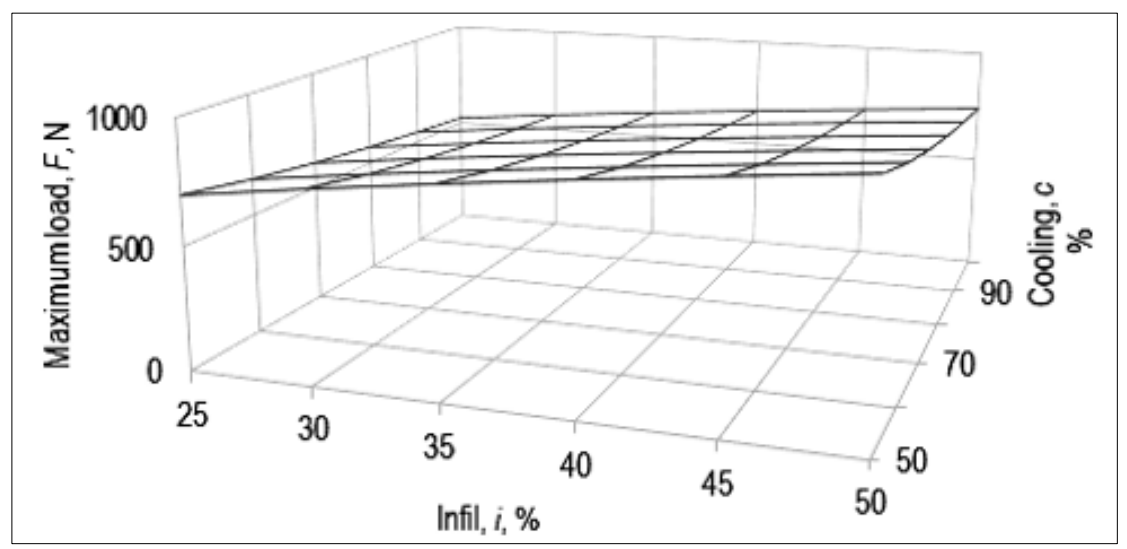

Figure 10. The influence exerted by the infil density $i$ and cooling conditions $i$ on the value of the load $F$ at which the maximum deformation occurs $\left(d_{\max }=10 \mathrm{~mm}, p=10 \mathrm{~mm}, n_{t}=3, t=0.06 \mathrm{~mm}, v=20 \mathrm{~mm} / \mathrm{s}\right)$

It is thus found that major diameter $d_{\max }$ has the greatest influence on the load $F$, since in the empirical mathematical way (1), this factor is assigned the highest value of the exponent, among the 7 exponents. The increase of the values of major diameter $d_{\max }$ of the number of turns $n_{t}$ in contact, of the infill $i$, of the thickness $t_{l}$ of the layer, of the velocity $v$ determines an increase of the load $F$, since the values of the exponents attached to the respective factors are positive. At the same time, the increase of the pitch values $p$ and of the cooling conditions $c$ leads to a decrease of the load $F$, since the values of the exponents attached to these factors are negative.

Increasing step $p$ causes a reduction in load $F$ and this can be explained by generating higher stress concentrators when step $p$ has higher values. A less clear explanation appears in the case of the printing speed $v$, the increase of which leads to an increase in the load $F$. This result could be explained to a certain extent by the different filling structure of the spaces inside the screw during the 3D printing process.

\section{Conclusions}

By the research whose results were presented in this paper, it was taken into account the highlighting of the influence exerted by some constructive dimensions (major diameter, pitch, number of contact turns with a special steel nut) and by some parameters of the 3D printing process (infill, layer thickness, printing speed, cooling conditions) on the tensile behavior of threaded rods. There is relatively little information in the accessed literature on such an issue. An experimental research program was designed, involving the tensile testing of polylactic acid screws obtained by 3D printing and using a special steel nut. In some cases, experimental tests showed the breaking of the threaded rod in different areas. By taking into account the input factors, an empirical mathematical model of power-type function was determined. The analysis of the empirical mathematical model highlighted the fact that the strongest 
influence on the load at which the maximum deformation of the threaded rod occurs is exerted by the major diameter of the thread. Increasing the major diameter leads to an increase in the load corresponding to the maximum deformation. It was also found that an increase in pitch results in a decrease in load, due to the more important effect of stress concentrator generated by a higher pitch value. In the future, there is an intention to expand theoretical research and experimental regarding the behavior of the outer cylindrical thread turns in the case of a tensile stress applied to the 3D printed threaded rod by means of the special steel nut.

\section{References}

1.FETECĂU, C., Injection of plastics (in Romanian), 2nd edition, Editura Didactică și Pedagogică R. A. Bucureşti, 2007.

2.PATPATIYA, P., SHASTRI, A., Additive manufacturing of thermoplastic M8 fasteners using photopolymer jetting technology for low-strength fastening applications, 2021. Available online https://www.researchsquare.com/article/rs-525671/v1 (accessed on 29.09.2021).

3.WANG, Y., CHEN, G., YANG, H., JING, J., A special thread design for failure prevention of expandable casing, Alexandria Engineering Journal, 60, 2021, 213-225.

4.SYDOR, M., WOŁPIUK, M., Economic justification for printing threaded joints for wood-based materials, Annals of Warsaw University of Life Sciences - SGG, W Forestry and Wood Technology 96, 2016, 145-150

5.LUSK, J., Mechanical Design for 3D Printing, 2012. Available online ahttp://eikimartinson.com/engineering/3dparts/ (accessed on 29.09.2021).

6.MACLEOD, A., PATTERSON, M., MACTEAR, K., SINGH GILL, H., 3D printed locking osteosynthesis screw threads have comparable strength to machined or hand-tapped screw threads, Journal of Orthopaedic Research, 38, 2020, 1559-1565.

7.SLĂTINEANU, L., Fundamentals of scientific research (in Romanian), Iasi (Romania), Publishing House PIM, 2019.

8.CRETU, G. Fundamentals of experimental research (in Romanian), "Gheorghe Asachi" Technical University of Iasi, 1992

Manuscript received: 3.11 .2021 